\title{
Learning through Linguistic Citizenship: Finding the "I' of the essay
}

\author{
Zannie Bock, Lauren Abrahams \\ and Keshia R. Jansen \\ University of the Western Cape
}

\begin{abstract}
In recent years, the South African higher education system has seen growing calls for broadened epistemic access, decolonised curricula and transformed institutions. Scholars across South Africa have taken up the challenge and are working on new theoretical approaches to teaching and learning in higher education. In this paper, we reflect on students' experiences of a multilingual, multimodal module called Reimagining Multilingualisms, which was jointly offered by the Universities of the Western Cape and Stellenbosch in April and May of 2018. In this paper, we provide an overview of the module and the different types of activities it involved. We reflect on these experiences using the theoretical lenses of decolonial scholar Mignolo (2009) on the 'locus of enunciation', and Stroud (2018) on 'Linguistic Citizenship'. We present extracts from focus group interviews with students from both campuses to illustrate the involvement of 'the body' in 'knowing' and the ways in which the module enabled different 'voices' to emerge. We focus particularly on the role played by students' perceived 'vulnerability' in the transformative benefits of the module and discuss this by way of conclusion. In sum, we suggest how the centring of multilingualism and diversity - not only as core pedagogic principles, but also as a methodology for transformation - may be used to enhance access and recapture voice in the building of a more integrated and just society.
\end{abstract}

\section{INTRODUCTION}

$\mathrm{T}$ his paper explores how a university module which employed nontraditional pedagogies (e.g. multilingual, multimodal, arts-based and creative writing methods) enabled new ways of thinking about language to emerge. The module in question is the postgraduate module, $R e$ imagining Multilingualisms. Historically, multilingualism as a feature of coloniality has to a large extent been about the erasure and hierarchisation of languages and speakers. Both historically and in contemporary time, it has comprised a technology in the bordering and governmentality of racialised bodies, determining what is taken to comprise a language and how the relationship among languages and speakers is construed, and their agencies regulated. On the other 
hand, multilingualism also holds out the promise of engaging different others in complex societies. Given this and the ubiquity of multilingualism in policy and practice in South Africa, re-imagining multilingualism is a definite priority. The overall aim of the module was therefore to re-think 'multilingualism' - not through language policy - but through tapping into the historically lived experiences - and imagination - of students from two local universities, the University of the Western Cape (UWC) and Stellenbosch University (SU). The different semiotic resources available to the students in each university are very differently valued, and understanding the rich historical backgrounds and differences between these institutions is essential to grasping some of the reasons for this, and understanding the issues that emerged during the process of 're-imagining'.

The University of the Western Cape was established in 1960 by the Apartheid state ${ }^{1}$ for 'coloured' students ${ }^{2}$, as part of the grand plan of segregated higher education. The University has historically served students from more marginal educational and social backgrounds. Today, the institution is still home to students who would selfclassify as 'coloured' or 'black,' although there is a small but growing number of white students (about 6\%). Students are generally bi- or multilingual and predominantly speak a combination of Afrikaans, English and isiXhosa, as well as mixed local varieties of these. English is the language of learning.

Stellenbosch University was established in 1918 for Afrikaansspeaking white students in the historic town of Stellenbosch, about $25 \mathrm{kms}$ from UWC. It has a complicated history as the alma mater of many apartheid leaders, and has historically served a much more elite community than UWC. Since the transition to democracy in 1994, it has worked to change its historical profile and culture, and to become more inclusive, but this process - as elsewhere - has been fraught. Although the student body is now racially much more diverse, the majority can still be described as white and coming from privileged homes. The language of learning is both Afrikaans and English.

The module, Re-imagining Multilingualisms, took place over five weeks in April and May 2018, on alternating campuses (UWC and SU). It was designed as an Honours (fourth year) module and included about seventeen students from SU and seven from UWC. The seminars were facilitated by a team of lecturers from both campuses, as well as visitors from Kings College London (KCL). It consciously broke with the more traditional 'lecture style' of teaching and used a range of alternative pedagogies. The first seminar was a workshop on Linguistic Ethnography by Professor Ben Rampton and colleagues from KCL. In the second session, students were taken through an associative mind-mapping

1 Apartheid - literally, with the meaning, 'separateness' - is the name given to the system of institutionalised racial segregation entrenched under white minority rule in South Africa between the years 1948 and 1994.

2 It should be noted that in South Africa, the term 'coloured' has a different meaning to the way it is used in the United States and elsewhere. Here, it refers to people of mixed heritage, many descendants of slaves from South East Asia brought here during the colonial times, or descendants of contact between the indigenous inhabitants of southern Africa and colonial settlers who began arriving nearly 400 years ago. Under Apartheid, all South Africans were classified either 'coloured', 'black', 'white' or 'Indian'. 
process of 'creating concepts' by a professor of Visual Arts from SU, Elmarie Constandius. In session 3, the participants created multilingual poems about 'home' in groups under the guidance of Kobus Moolman, professor of Creative Writing at UWC. In the fourth session, they went on 'narrated walks' around Stellenbosch - so as to become aware of themselves in relation to different semiotic landscapes and built spaces - in a session facilitated by Amiena Peck of UWC. In the final session, students considered the intersections between syntax and a political philosophy of language, Linguistic Citizenship, in a session facilitated by Erin Pretorius and Quentin Williams, also of UWC. After each session, students were asked to write reflective pieces or poems about their experiences, or make something artistic, all of which were presented in an exhibition at the end of the module. These written texts and artefacts, along with two focus group interviews held with students from both universities, serve as the data for this paper.

In our analysis of the data, a number of themes emerged. In this paper, we will only present the ones which were most generative, namely, the centrality of the body and embodied knowledge to understanding students' experiences of language and learning. The core argument we make is that what proved central to triggering quite profound shifts in epistemic awareness and learning among our participants was the discomfort caused by the movement of (student) bodies between historically very different campuses comprising different linguistic ecologies and semiotic landscapes. Being 'forced' into contact with each other, we argue, enabled, over time, new convivialities and perspectives to emerge; in other words, the students learnt to see 'through other eyes' (Andreotti and De Souza, 2008).

\section{LITERATURE REVIEW}

\section{The decolonial approach}

Our theorisation of this argument draws on decolonial theory, as proposed by, among others, De Souza (2014) and Mignolo (2009), and the emerging theory of Linguistic Citizenship (cf. Stroud 2001, 2018). The general sentiment among decolonial scholars, including Mignolo (2009, 2013) and Baker (2012), is that all knowledge is shaped by the geo-political context in which it is produced. In other words, knowledge has a locus of enunciation - which reflects the ideological underpinnings (of modernity, science or race) that structure these contexts. However, this situatedness is often concealed by the Western belief that scientific knowledge is 'neutral' and 'universal.' Baker (2012) refers to this view of knowledge as a decontextualised 'truth.' Knowledge is therefore presented as science, which is not to be contested. When knowledge is decontextualised, it becomes separated from its knowledge producer. According to Mignolo (2013), Western views place emphasis on suppressing the 'sensing' and the body of the person who possesses or creates the knowledge. Separating the knowledge from the knowledge producer therefore hides the locus of enunciation.

The body is the point of enunciation, and thus when the locus of enunciation becomes hidden - when the ' $\mathrm{I}$ ' is removed from the knowing - the embodied nature of knowledge is lost sight of. According to Lynn Mario T.M. de Souza (see 'Decolonial pedagogies, multilingualism and literacies' in this journal), the decolonial approach is about reconnecting the mind with the body - the physical body as well as the body's history and memory - its joys, 
fears, and different ways of knowing. Decoloniality therefore seeks to bring the focus back to the embodied self and acknowledge the role of contextual factors in knowing. Within education, this involves exploring the many different ways of knowing that tap into the positionality and corporeality of the body and its sensibilities.

\section{Linguistic Citizenship}

Linguistic Citizenship (LC) is a conceptual tool designed to address the various ways in which language, particularly multilingual practices, mediate political subjectivities. LC is fundamentally about theorising how language and multilingualism opens up, or forecloses, opportunities for speaker agency, and how linguistic practices are formative in the political subjectivities of individuals or groups. It is about how individuals come together - emerge - as constituencies of speakers, either in pursuit of short term interests or for longer term goals, and it is about the nature of those repertoires and practices that facilitate this. Importantly, LC goes beyond what we might habitually associate with the notion of citizenship, namely, rights claims or questions of inclusion versus exclusion in recognised political entities (be these states, nations, cities, minority groups). It is fundamentally about the broader question of how speakers claim autonomous selves and subjectivities and manufacture alternative constituencies - often on the cusp of, or outside of, or in the interstices and hidden spaces of, established ones. It is about the way in which established regimes of language are reworked in these 'marginal' and unacknowledged spaces in search of alternative political subjectivities, or agencies. It is about how these new or alternative linguistically constructed constituencies (or socialities) go beyond those that are institutionally recognised and designated by the established, historically arbitrary language labels that are linked to the official discourses of power. The situation of Afrikaaps (or Kaaps), the stigmatised, Western Cape variety of Afrikaans, and the ways in which this is being variously re-claimed, is a case in point (cf. Stroud, 2018).

In this study, we underscore the affinities between LC and the notion of pluriversality introduced by the philosopher Hannah Arendt. Arendt (1958) uses pluriversality to refer to a multiplicity of voices. Pluriversality and the recognition of individual voices by others are seen as fundamental to the formation of individual subjectivities. Pluriversality is also the condition for action as well as a prerequisite for freedom. On the one hand, individual subjectivities are formed in our engagements with a multitude of others: to act (and to speak) is to disclose, reveal, and unveil oneself in front of or, better, together with others. It is through action and speech that the self is revealed. Action discloses the identity and unique individuality in actors/subjects and gives them political agency. This does not imply an essentialist identity preceding the act of disclosure, but rather its public co-construction.

In a similar way, pluriversality, as the prerequisite for freedom, is only successfully attained to the extent that actions and discourses in the political sphere gain recognition by a plurality of others who are also actively partaking in the public sphere. To be free, then, is to have the capacity to act, to be uniquely recognised by a plurality of others, and to exercise the capacity "to begin", that is, natality. Pluriversality in this sense is the precondition for action, at the same 
time as it is what constitutes the unique identity of the individual. Thus 'selves' are constituted when their actions and discourses are 'taken up' by multiple others in public spaces.

\section{RESEARCH AIMS AND QUESTIONS}

The main purpose of this paper is to explore how students responded to and engaged with the module, Re-imagining Multilingualisms, and the extent to which their experiences enabled shifts in their perspectives, in relation to both language and learning and their relationships to others. Our theoretical framing in LC and the decolonial body suggested the following questions:

1. What happens when students are able to use the full range of their multilingual and multisemiotic resources in their university studies, and does this enable voice and agency?

2. What role does the body and embodied knowledge play in learning and the development of new knowledge?

3. To what extent does the interuniversity nature of the module lead to new socialities and fresh perspectives on language, self and others?

4. How does Linguistic Citizenship help us re-think and re-imagine multilingualism as a transformative dynamic?

\section{METHODOLOGY}

Given the nature of the research questions, we adopted a qualitative approach. According to Madill and Gough (2008), qualitative research focuses on the variable meanings and interpretations that various participants bring to an issue. Similarly, Stake (1995) suggests that one of the defining features of qualitative research is that it seeks to understand the complexities of a particular phenomenon or social reality, rather than simply describing or quantifying it as an observable phenomenon. It is clear that the uncovering and understanding of these meanings, that may or may not be concealed, are fundamental to this approach. Madill and Gough (2008) point out that interviews, surveys, focus groups and observations are among those data collection techniques typically used for qualitative research.

Furthermore, the study is ethnographic in nature. Because ethnography is inductive (Blommaert \& Jie, 2010), the data guides the theorisation rather than the converse. Central to ethnographic research is the process of entering the lives of a social group or community and attempting to understand seemingly inexplicable practices that structure that community from the perspective of that community (Rampton, Maybin \& Roberts, 2015). In other words, the researcher enters the group of enquiry and participates in the activities they perform while trying to make sense of these activities. Lauren Abrahams and Keshia Jansen, two of the authors of this paper, were the research assistants on the project and participated in the module as ethnographic researchers. They also conducted the two focus group interviews with the students of the two universities, the contents of which form the main source of data for this paper.

The first focus group interview took place at SU in May 2018 once the module was completed, and included eight female students. Given that race becomes an important topic in this 
analysis, it is pertinent to mention that the group included students who selfidentify as white (five) and coloured (three). All students reported that they were fluent in both English and Afrikaans. Some students also reported having languages like German, Korean, French and isiXhosa in their linguistic repertoires.

The second focus group interview was held with four students from UWC who were also participants on the module. This group included one student who self-identifies as coloured and three as black. The interview took place in the Linguistics Department in June 2018. All the interviewees were fluent in English, as well as a range of other languages such as Standard Afrikaans, Kaaps, isiXhosa and isiZulu. Kaaps is spoken by many coloured students at UWC.

The interviews followed a semistructured format and participants were encouraged to raise anything that they felt was relevant so as to broaden the scope of the discussion. This allowed the participants and the interviewer to explore topics which piqued their interest. The interviews were audio recorded, transcribed and analysed using thematic analysis. According to Attride-Stirling (2001), thematic analysis is an inductive procedure which uncovers and explores the themes that are most significant in a text at different levels. In addition, it allows a sensitive, perceptive and rich examination of a text's obvious and hidden patterns (Attride-Stirling, 2001).

This process of data analysis was jointly conducted by all authors during a full day workshop. After listening to the audio recordings and studying the transcripts several times, we began a process of coding the data. Coding involves reducing the data into smaller segments that are easier to work with
(Attride-Stirling, 2001). Instead of devising a coding framework and applying it to the data, we worked from the data up. The codes are based on recurrent words or ideas that were raised during the interview along with specific moments that were deemed significant. These codes were then grouped into themes, on which our analysis is based.

Although the interview data is the primary source for this paper, the other ethnographic data, such as photographs and field notes, were used to complement the thematic analysis and situate the analysis in a particular context.

\section{DATA ANALYSIS}

The main themes to emerge, and which are explored in this section, include: (1) Moving out of comfort zones, (2) Food and conviviality, (3) Being 'boxed' in, (4) New ways of seeing, and (5) Re-discovery of the "I".

\section{Moving out of comfort zones}

This first theme gets to the heart of our analysis, namely the embodied nature of learning, and the ways in which shifts in perspective were triggered by the movement of student bodies between campuses. Protecting our bodies is the most basic human instinct. The minute our bodies are placed in new environments, we tend to respond differently compared to when we are in our comfort zones. The centrality of the body became evident and is illustrated in students' experiences of moving into different spaces. As already noted, the two universities in question have very different histories and cater for very different student groups.

Recounting the first time she entered the SU campus, Thuliswa, a UWC student, noted: 
1. I think when we - when we got there ... the first thing I noticed was that were the surroundings I was ooh this is VERY fancy.

Her description of SU as 'VERY fancy' is significant. It serves as an acknowledgement that she has entered a space that is significantly different to that which she had expected or to which she is accustomed. The idea of being in a 'fancy' place usually evokes the expectation of having to conduct oneself in a certain way. This raises the question of whether Thuliswa felt as though she needed to behave or speak differently upon entering this 'fancy' place. In other words, it points to how her perceptions of the space and the power relations that operate in this space regulate her awareness of her own body and her behaviour.

The perception of $\mathrm{SU}$ as a rather 'up-market' place was shared by all of the UWC participants. This perception manifested at various points during the interview as well as in the experiences of other UWC students on first arriving at SU. For instance, students paused and marvelled at the buildings, sculptures and various other features which the majority of the SU students regarded as normal or mundane. This was particularly noticeable during an unscheduled tour-like walk through Stellenbosch led by some of the senior SU students. The UWC students took pictures and admired the scenery throughout the walk as if we were on an excursion. This perception of SU as notably different and elite shaped the way the participants perceived and experienced the events they encountered there.

Sihle, a UWC student, speaks directly to this in the following anecdote, where she begins to describe her first experience at $\mathrm{SU}$ :
2. Sihle: so for me the-my first time was also when we went to Stellenbosch [clears throat] and firstly what I noticed was like how everything is written in Afrikaans and how the security guard or the uhm gardener pointed us in - to where we were supposed to be in Afrikaans == Keshia: $==$ oh yes I [ [remember

Gia: [[mm

Sihle: I feel like he can see our skin complexion he can see that ... [soft giggle in the background] ...

Gia: I think [[Stellenbosch is

Sihle: [[we might not understand

One of the first things Sihle noticed was that the space was dominated by one language, Afrikaans. Earlier in the interview, Sihle tells the group that her home language is "isiXhosa with a mix of Kaapse Afrikaans”. From this we can establish that she is familiar with one variety of Afrikaans that is closely linked to the standard variety which appears in the signage at SU. The two are mutually intelligible, to a point. Even though she may have been able to read the Afrikaans signs, they still stood out to her as a marker of the different space. It is noteworthy that the majority of the signage at UWC, a space in which she spends most of her time, is in English. In the above lines, Sihle expresses her disapproval of being addressed in Afrikaans by a person who appeared to belong in this unfamiliar space. It is not uncommon for students to be addressed by other students, or even some staff, in Afrikaans or Kaaps at UWC. In fact, Keshia recalls that she has previously spoken to Sihle using Kaaps words and has not experienced a negative reaction. However, here she appears deeply offended by the above incident, making clear reference to her body, specifically 
her race. Interestingly, the man in question was a gardener and would most likely self-identify as coloured. Entering this strange place caused Sihle to be highly aware of her own racialised body. It is as if her awareness of being in a strange space, and perhaps a perception of herself as an outsider, compelled her to interpret the incident as offensive, without giving much thought to any circumstantial factors. For instance, she did not consider that perhaps the gardener may not have been a speaker of English.

However, it is not the physical space (SU) alone that caused discomfort to the participants. The presence of 'other' students was also a source of unease to Anathi, a UWC student. Anathi describes the arrival of the SU students in the first session of the module, which was held at UWC, as 'an invasion':

3. I felt invaded like by all these [accent changes to a more animated one] blonde people [laughter] 'cause we just don't see them often on this campus.

Even though the space itself was one she was familiar with, as it was UWC, she was made uncomfortable in it by being surrounded by other bodies who do not look like her. Anathi goes on to say that she felt lost because she could not see "her people", underlining how 'the body' is inclined to cling to the familiar in order to feel safe.

Another UWC student remarked that upon arriving in Stellenbosch, she noted that "it looks like our ancestors built the place”. This comment acknowledges the colonial power of the space itself, as her ancestors would most likely have been slaves there. This kind of discomfort was common to students of both universities. Similarly, the Stellenbosch students also registered their discomfort at entering a different univesity:

4. Amanda: We've all been here (at Stellenbosch) at least for like four years so we don't really (all of a sudden) to be somewhere else in a different university ... quite a shock to your system in the beginning.

This feeling is echoed by Tammy, another SU student:

5. I was very uncertain about it cause I hate being outside of my university grounds [laughter] uhm ja, ja, I was nervous about going, uhm, but then my perception kinda changed towards it, at the end it was more easy, and the lunches were very nice.

The mention of lunch in this extract is another recurrent theme which emerged as significant, and eased the discomfort caused by being out of one's comfort zone. This theme is explored in detail in the next section.

From the above, it is clear that the movement of bodies into new spaces, spaces far beyond their comfort zones both in distance, and in historical linguistic and racialised backgrounds, resulted in intense feelings of discomfort. This focus on the body finds resonance with the decolonial theory of 'locus of enunication'. In this journal, Lynn Mario De Souza talks about knowledge as embodied, emphasising yet again the notion of the locus of enunciation, or "the space from which we speak." De Souza notes that acknowledging the space from which we speak situates the body in space and time and thus highlights the embodied nature of knowledge and knowing, and that this view is a challenge to the Western notion that knowledge is decontextualised and universal. Acknowledging the bodily discomfort 
caused by moving into different spaces makes visible the decolonial notion that knowledge and knowing, including what we 'know' through the visceralities of the body, are, in fact, highly contextualised. This reconnection with the body was a recurring topic throughout the module.

\section{Food and conviviality}

A second dominant theme to emerge from our data involves 'food and conviviality', both closely linked to the body. When SU students were asked about the highlight of the module, the first topic to arise was food. Not only was the food delicious, they said, but it became a focus of engagement for the students from the different campuses. Simply put, feelings of conviviality emerged as a result of the food and eating together. This is because students could use food as a topic of conversation and this opened up a space for sharing of not only food, but perspectives as well. Shané, a SU student, notes:

6. Obviously you don't expect to get food for a course and then it was such nice food and they catered for everyone, uhm you know being vegan or vegetarian or whatever there was always something for everyone to eat.

Food is not usually expected and given for a module; however, it was a pleasant surprise for students and they really enjoyed the experience. Furthermore, Shané talks about how "they catered for everyone". This is indicative of the diversity of students, who were not only diverse in dietary requirements and preferences but in other aspects as well. Another SU student, Tammy, adds: "the lunches were very nice" and all students agreed that the food was important in helping students to socialise and find commonality.

This socialisation is also a feature of Lauren's own reflections where she recounts how (in the second session lunch break) she accepted a "fish lollipop" from a Stellenbosch student (Tammy) who asked if anyone wanted her fish stick. While Lauren interpreted this as a gesture of conviviality, this same incident was interpreted very differently by the UWC students who were offended by it, as seen in the following extract from the UWC interview:

7. Anathi: she turns around after she's eaten everything of hers and she realises she doesn't like the fish stick if you don't like it take it back - she turns around and she looks at - "would any of you like this fish lollipop?” [[bitch

Keshia: [[that she's already eaten on?

Anathi: that she's already - no she didn't eat it she looked at it she ate the whole food $=$

Thuliswa: $=$ haa $=$

Anathi: = her leftovers she turned around and gave to someone else I was like "okay first of all ... girl ... boundaries" [laughter] but anyway I would've said something else but ja I just looked at her like I'm not gonna reply to this and as time went by she proved to me like she's exactly who $\mathrm{I}-\operatorname{not}=$

Thuliswa: $=$ assumed $=$

Anathi: $=$ there were no preconceived ideas but when you know it just ja it was that okay I know where you stand in relation to who you think you are and who you want to be but anyway we're not there

Gia: I must say though she opened 
the floor to some very interesting $=$ Anathi: $=$ interesting insights $=$ Keshia: $=$ aah definitely $=$

Here Anathi, a UWC student, expresses feelings of offense and discomfort towards the act of being offered "leftovers". Although this act may have been intended as a gesture of conviviality, and Lauren interpreted it as such, the UWC focus group responded negatively. Their response is indicative of the general suspicion and lack of trust initially felt by the UWC students towards the SU ones, which was also, no doubt, shaped by and in response to the perceived (and real) power differentials.

Despite this incident, the presence of food on the module, to be shared together, enabled some conviviality to emerge. While initially students sat in their 'own groups' to eat, as the module progressed, they were seen eating together and engaging with each other. Ultimately, this new sociality helped to set in motion a series of events that led to significant shifts in students' attitudes and perspectives, and began a process of change (or 'unlearning' and 'relearning').

\section{Being 'boxed' in}

The next significant moment in this process occurred with the mention of the 'boxes'. During the second session in which students used arts-based methods to create concepts, one of the UWC students had a moment of realisation that society will always put us into 'boxes', and she was quite upset about it. By 'boxes', she was referring to the racial categories which continue to shape the way we see each other in South Africa. Once Sihle expressed her views, a platform was created for students to share their thoughts on the matter. Soon after, many other students came forward with their thoughts, thereby opening a space for a sharing of perspectives. For instance, one student revealed that she felt obligated to use the standard variety of Afrikaans among her peers instead of Kaaps to avoid being associated with the negative stereotypes that surround the latter. Thus this second session created a platform for students to share their thoughts and gain insight on the views and understandings of others whom they perceive as different. The atmosphere among the students was notably different following this session. Sihle's 'boxes' were joked about but also served as an entry point for many serious conversations throughout the module. One SU student remarked:

8. When we started joking about uh boxes and how we didn't like the boxes and like we didn't like to be put in a box or labelled and we all joked about that and it became funny between the UWC students and the Stellenbosch students as a group of students not as separate universities.

It then became clear that the aversion to being categorised and labelled transcended race and class, and was an idea that students of both universities could relate to. This incident served as a turning point for students in the module.

\section{New ways of seeing}

The creative writing session was the third session in the module and it was this seminar which triggered the most profound shift in the way students related not only to each other but also to their own linguistic repertoires and 
sense-of-self as knowledge producers. Students were organised into groups by the facilitator (Kobus Moolman), which 'forced' UWC and SU students to work together. The groups were then encouraged to write collaborative and multilingual poems on the theme of 'home'. In our view, this was the session which helped the two cohorts of students to interact, overcome some of their shyness and suspicions, and begin to discover 'new ways of seeing' (Andreotti and De Souza, 2008). Here Sihle, who had up to now been quite suspicious of the SU students, describes how this session changed her perceptions, as she realised there were similarities between her and the US students:

9. The whole thing was about home like a home so then we got a sense of you got like a bit of intel on their lives personally which was very interesting it even changed our - my perceptions of some of them 'cause I was like "oh cool your mom also gives you a nickname"

Additionally, this interaction between the two cohorts allowed for a change in perceptions about language. This can be seen when Gia, in one of her written reflections, comments on how the creative writing session was a turning point for her as she found writing in both English and Afrikaans liberating:

10.I think this seminar was the one that opened my eyes to the rich possibilities of multilingual writing. This seminar proved that when one is allowed to write in one's own language, knowledge is unlocked. The writing ceases to simply be a written piece of work and becomes something that embodies culture and identity.
Gia further recounts another significant shift in perspective that the module triggered for her. She admitted to believing, all her life, that Kaaps was inferior to the standard variety of Afrikaans but that her experiences on this module had changed this position. The variety of Afrikaans with which she was raised and with which she identifies is standard Afrikaans. Gia writes:

11.I have a very particular and special connection with standard Afrikaans. I have always viewed it as superior to Kaaps. Admitting I was wrong about Kaaps ... Die ondier het toe in ' $n$ prins verander, of altans is besig om in $\mathrm{n}$ prins te verander. [The beast/monster has changed into a prince, or at least is busy changing into a prince.] I stigmatised and looked down on it, thinking my own is superior because society told me (and is still telling me!) mine is better ... I see Kaaps/Afrikaaps differently now

\section{Re-discovery of the "II"}

These and other moments of shift accumulated for many students in the re-discovery of the "I", as expressed by these SU students in the following extract:

12.Ava: When I wrote my reflections I got to write in first person and I got to say like $=$

Shané: $=\mathrm{I}=$

Ava: $=$ JA I loved that $=$

Jenna: $=$ Ja $\ldots$ you are you are taught from first year that $\mathrm{I}$ is never used you are not important in your essay ...

Sara: We were all saying about the creative element it was nice to kind of get back into that uhm - get in 
touch with that side of myself cause you know you lose that in university.

Here the four participants share how the space to be creative enabled them to reconnect with their sense of 'I'. In decolonial terms, it enabled a discovery of voice and a recovery of the locus of enunciation. Another SU student, Cindy, added that she "enjoyed being creative", and "doing something other than just writing". This shows how she liked that the course departed from the usual lecture and assessment style. Similarly, Jamie mentions that:

13. Masters students who didn't take part, when seeing the exhibition mentioned that it was such a - like - creative or like diverse, different way of teaching and a different way of learning and I think we can all agree to that it wasn't uuh your standard 'this is our lecture' we did have lectures now and then or like in the course but I really really liked that it wasn't, it was such a creative learning experience

This illustrates how the freedom to be creative enabled the students to enjoy the module more than they would a regular essay writing module. It also allowed them to do things like "draw again", as it drew on the range of their semiotic resources, thereby deviating from the dominant mode of academic assessment. Additionally, students were encouraged to write multilingually, and some lecturers also used their own multilingual repertoires when teaching. Mia reflects on how "it was nice to get away from like the academic side for a bit and like I also enjoyed the group poem that we did that was really fun". In addition, Anna, another SU student, mentions that she liked that:
14. We got to do site visits and actually leave the whole like classroom environment cause even as a student it was the first time I was at Goldfields, and in a res that was off campus and stuff and it was it was interesting just to see like different parts of Stellenbosch which I thought was cool.

The mention of Goldfields in this extract refers to the narrated walking session, where students walked around various parts of Stellenbosch. This took students from both UWC and SU out of their comfort zones, as many of them had never physically been in these spaces, even those from SU itself.

\section{DISCUSSION}

In this paper, we have explored the ways in which experiences on an interinstitutional module, using arts-based and creative methodologies and modes of learning, has helped us re-think and re-imagine multilingualism. What proved key to enabling students to shift their perspectives on language and learning, was the discovery of themselves in relation to other students and campuses, or, an awareness of the centrality of their bodies in 'being' and 'knowing' i.e. the locus of enunciation. We see how the awareness of self, particularly of one's racialised body, opened students up to new learning. In other words, the re-evaluation of learning, and the shift in understandings of language and multilingualism very much emerged out of students' repositioning of their corporeal Selves in relation to Others. A key dynamic here was their engagement with pluriversality (Arendt, 1958), the bringing together of many voices in a concerted conviviality, allowing a new subjectivity and sense of 
actorhood among speakers as people and knowledge producers. This, and the resultant new conviviality across difference that developed overtime as students worked with new notions of language and multilingualism, is an illustration of the exercise of Linguistic Citizenship (LC) in practice.

Our analysis shows that when we look closer at what students' corporeal positioning entailed, we find evidence that it was accompanied by significant discomfort and disorientation. First of all, the movement of bodies across spaces, both physical and social, took students (and lecturers) out of their comfort zones. Secondly, the module required all participants to draw on their full linguistic and multisemiotic repertoires. This made some people feel uncomfortable, anxious: "I'm not creative, I can't possibly write a poem, or draw a picture ... Can I speak Kaaps in a university setting? ... I don't understand syntax". In a way, everyone was 'disadvantaged' in some way: some are better at poetry, others at making objects, some at syntax. Thirdly, the module opened a space for students to reconnect learning with their affect, emotion and imagination, and in the words of Ava, to rediscover the 'I' in her writing, what we have referred to as the 'locus of enunciation'. Thus, a key feature of the module, evident across student comments, was that participating with unknown others and with differently valued languages and varieties, created feelings of vulnerability. Importantly, it was also vulnerability that led to the condition of openness to others that offered the potential for students' alternative engagement with selves allowing them to reposition themselves vis $a$ vis each other and language. It was the discomfort, in fact, that became a key to shifts in epistemic awareness and learning, allowing new convivialities and perspectives to emerge. A clear example of this was the creative writing session where students wrote collaborative, multilingual poems. One of these poems had four languages: Afrikaans, isiXhosa, English and Portuguese. There was no one in the group who knew all four languages. So it took a group to produce the poem, and a group to interpret it - in other words, there was no single author, or authority, but a convivial new sociality.

Vulnerability, then, is a useful lens with which to approach the experiences of the students. On the one hand, being vulnerable is precisely what opens us to discomfort, while, on the other, it simultaneously comprises a condition of openness to others, and carries the potential for alternative engagement with selves. The notion of vulnerability also finds resonance with Arendt's notions of pluriversality, as it is the human capacity for action (pluriversality) that continually brings forth newness and makes the world unpredictable, and its inhabitants subsequently vulnerable. Thinking about vulnerability in conjunction with Arendt's notion of pluriversality highlights the relational aspects of mutual dependence, as conditions of vulnerability require joint, collaborative 'interventions' to ameliorate and benefit from change. Both vulnerability and pluriversality comprise the building blocks of LC, which following Stroud (2018: 5), can be described as "an approach to a politics of language and multilingualism that departs from a notion of vulnerability, in the sense of the emergent and sensitive process of disinhabiting, stepping out of, imposed and linguistically mediated and entangled subjectivities".

An important feature of LC is the variety of semiotic means that it recognises as articulations of agency. In this regard, a characteristic of the 
module throughout is the abundant use of transmodality, that is, the multimodal, multilingual, multisemiotic features, and, in particular, the crossing of modes, genres, styles, languages, even spaces. This was important in enabling the students to break the established, naturalised modes of academic practice and to begin thinking about themselves and their linguistic repertoires differently - all the time accompanied by feelings of discomfort that engaged their creativity and enabled them to re-discover their sense of self and voice, and to begin to see things 'with new eyes'.

\section{REFERENCES}

Andreotti, V. and De Souza, L.M. 2008. Learning to read the world through other eyes. Derby, UK: Global Education.

Arendt, Hannah. 1958. The Human Condition. Chicago: University of Chicago Press.

Attride-Stirling, J. 2001. Thematic Networks: An Analytic Tool for Qualitative Research. Qualitative Research, 1 (3): 385-405.

Baker, M. 2012. Interpreting, Researching \& Transforming Colonial/Imperial Legacies in Education. Presentation at the American Educational Studies Association Annual Conference: Seattle, Washington.

Blommaert, J. \& Jie, D. 2010. Ethnographic fieldwork: A Beginner's Guide. Great Britain: Multilingual Matters.
De Souza, L.M. 2014. Engaging the global by resituating the local: (Dis)locating the literate global subject and his view from nowhere. In Andreotti, V. \& De Sousa, L.M. (Eds), Postcolonial Perspectives on Global Citizenship Education, New York: Routledge. 68-83.

Madill, A., \& Gough, B. 2008. Qualitative Research and Its Place in Psychological Science. Psychological Methods, 13(3): 254-271.

Mignolo, W. (2009), Epistemic disobedience, independent thought and de-colonial freedom, Theory, Culture and Society 26(7-8): 159-181.

Mignolo, W. 2013. Geopolitics of Sensing and Knowing: On (De)coloniality, border thinking, and epistemic disobedience. Confero, 1 (1): 129-150.

Rampton, B., Maybin, J., \& Roberts, C. 2015. Theory and method in linguistic ethnography. In S. Shaw, F. Copland, \& J. Snell. (Eds.) Linguistic Ethnography. London: Palgrave Macmillan. 14-50

Stake, R. 1995. The art of case study research. California: Sage.

Stroud, C. 2001. African mother tongue programs and the politics of language: Linguistic Citizenship versus Linguistic Human Rights. Journal of Multilingual and Multicultural Development 22 (4): 339-355.

Stroud, C. 2018. Introduction. In Lim, Stroud and Wee (Eds). The Multilingual Citizen. Multilingual Matters. 1-14. 


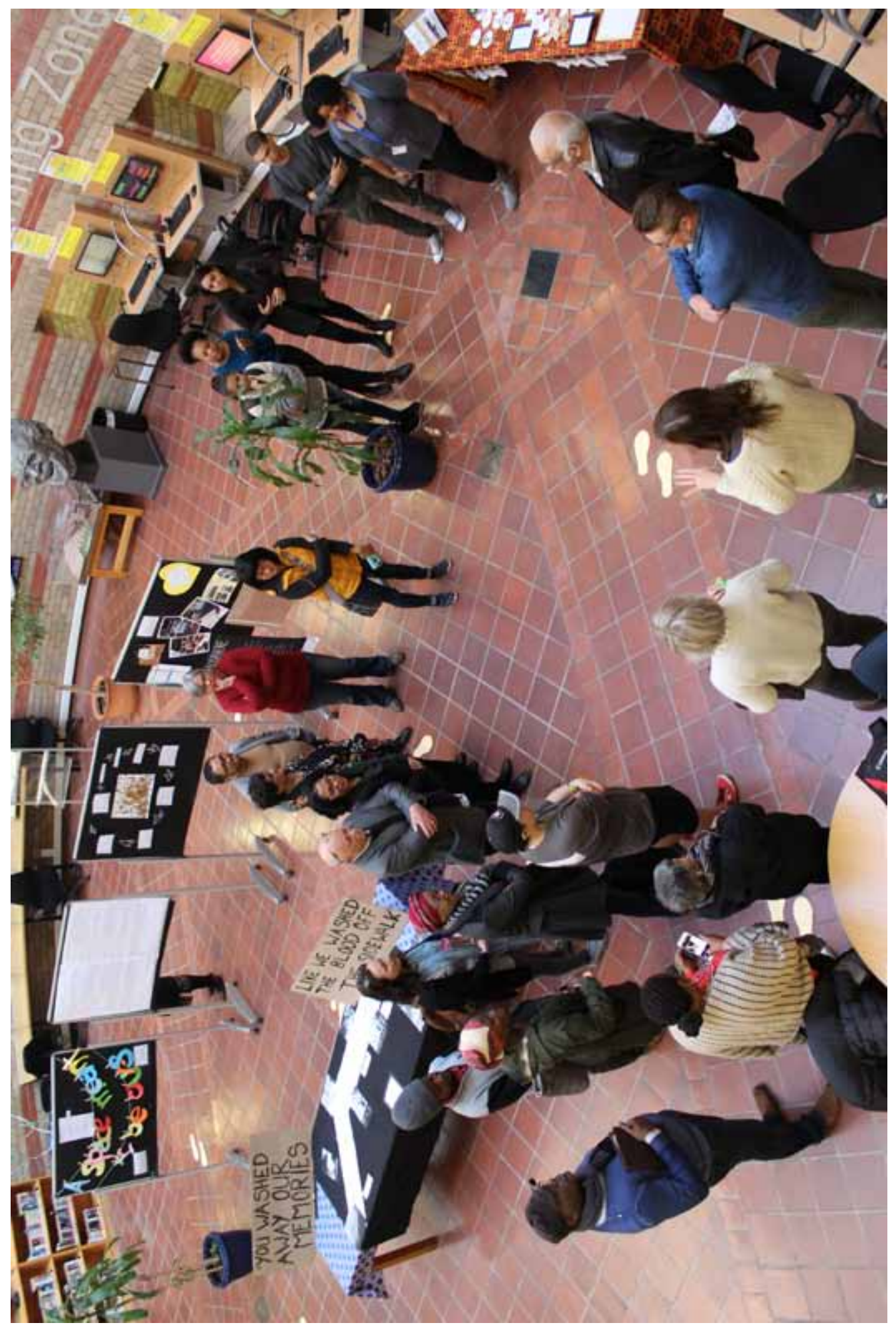

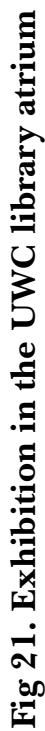

(C) CMDR 2019 